EXTENDED REPORT

\title{
Improvement of coping abilities in patients with systemic lupus erythematosus: a prospective study
}

\author{
M Haupt ${ }^{\star}$, S Millen*, M Jänner, D Falagan, R Fischer-Betz, M Schneider

See end of article for authors' affiliations

......................

Correspondence to: Prof Dr Matthias Schneider, Centre of Rheumatology, HeinrichHeine-University Düsseldorf, Moorenstr 5 , 40225 Düsseldorf Germany; schneider@ rheumanet.org

Accepted 3 April 2005 Published Online First 13 April 2005

Objective: To evaluate a novel specific psychological intervention aimed at improving coping in patients with systemic lupus erythematosus (SLE).

Methods: 34 community living SLE patients were recruited for the study. Intervention was undertaken in groups of up to eight patients and in two blocks over six months each. Eight patients were enrolled as a waiting list group. The 18 group sessions focused on information about the disease and specific problems of SLE patients, combining psychoeducative and psychotherapeutic elements. Psychological and medical evaluations were conducted at baseline and after three, six, and 12 months, using validated instruments. Results: The 34 SLE patients (91\% female, mean age 42 years) improved significantly over a six month period on most of the psychological measuring instruments applied, such as depression, anxiety, and overall mental burden. The waiting list group showed no significant changes.

Conclusions: Conceptualised psychoeducational support may produce a significant and sustained .................... improvement in coping skills of SLE patients and hence in their quality of life.

D epending on its course and on the patient's individual situation, systemic lupus erythematosus (SLE) can lead to a wide range of physical, mental, and social problems. These include fatigue, ${ }^{1-7}$ sleeplessness, ${ }^{8-10}$ cognitive dysfunction, ${ }^{11}$ neuropsychiatric symptoms, ${ }^{12}$ lack of self efficiency or control over the disease, ${ }^{13}{ }^{14}$ reduced stress threshold,,$^{15}$ depression ${ }^{16-19}$ or anxiety ${ }^{20}$ or both, ${ }^{21}$ and a poorer quality of life than healthy subjects. ${ }^{22}$ There are indications that involvement of the central nervous system entails an increased risk of suicide. ${ }^{23}$

The course of the disease and the mental wellbeing of SLE patients are influenced by the kinds of coping strategies, ${ }^{24-26}$ social support, ${ }^{27-29}$ and the ability to deal with stress and negative emotions. ${ }^{19}{ }^{2130}$ The published data on the episode precipitating effect of stress in SLE patients are contradictory. ${ }^{31-33}$

Adequate coping strategies, social support, and the ability to deal with stress and negative emotions can enhance mental and physical wellbeing in SLE patients. Various studies have underscored the need for supplementary psychological support. ${ }^{11} 1319263034-36$

Approaches published to date for providing SLE patients with supplementary psychological support can be divided into psychoeducational interventions and those based on psychotherapeutic counselling. Psychoeducational concepts are found in patient training programmes-focused on providing information on symptoms and therapeutic approaches $^{37-39}$ or giving greater emphasis to the coping response to illness and everyday life ${ }^{40}$ - and in self management courses. ${ }^{41}{ }^{42}$ Approaches based on psychotherapeutic counselling include telephone counselling ${ }^{43-46}$ and short term group psychotherapy based on the concept of brief supportive-expressive group psychotherapy. ${ }^{47} 48$

In the present explorative study, we developed a group intervention tailored to the specific needs of SLE patients, integrating psychoeducational elements while retaining the fundamental nature of short term group psychotherapy. We assumed that such an integrative intervention would be of greater benefit to SLE patients than former singular therapeutic approaches. The effects of this newly developed psychological intervention on depressive symptoms and anxiety were investigated in this present study. Improved coping ability at six months was therefore the primary aim.

\section{METHODS}

The group intervention was conducted at the department of rheumatology, Heinrich-Heine-University, Düsseldorf from 1 April 2002 to 31 March 2003.

Patients were recruited to the study through the following channels: outpatient department of rheumatology, HeinrichHeine-University, Düsseldorf; private rheumatological practices; local rheumatology hospitals; and the German Lupus Erythematosus Self Help Group.

All patients gave their written informed consent. The ethics committee of Düsseldorf University raised no objections to the proposed group intervention.

Inclusion criteria were the presence of SLE according to American College of Rheumatology (ACR) criteria, minimum age 18 years, minimum disease duration three months, stable health situation, low disease activity at enrolment, and an abnormal rating in at least one subscale of the symptom checklist 90, revised version (SCL-90-R).

Exclusion/discontinuation criteria were hospital admission because of an acute episode, diagnosed psychiatric disorders, severe speech problems, predictable failure to attend group sessions regularly, more than four sessions missed, ongoing external psychotherapy, ongoing participation in a clinical study, pregnancy, dementia, and life threatening concomitant disease.

\section{Test procedures}

The following standardised instruments were used within the framework of the study: symptom checklist 90, revised

\footnotetext{
Abbreviations: ACR, American College of Rheumatology; ECLAM, European consensus lupus activity measurement; FAL, everyday life questionnaire; FKV, Freiburg questionnaire on coping with illness; HADS-D, hospital anxiety and depression scale-German version; KKG, questionnaire for registration of control convictions relating to illness and health; SCL-90-R, symptom checklist 90, revised version; SESA, self acceptance registration scale; SF-36, short form 36 item general health questionnaire; SLE, systemic lupus erythematosus; SLICC, system lupus international collaborating clinics
} 


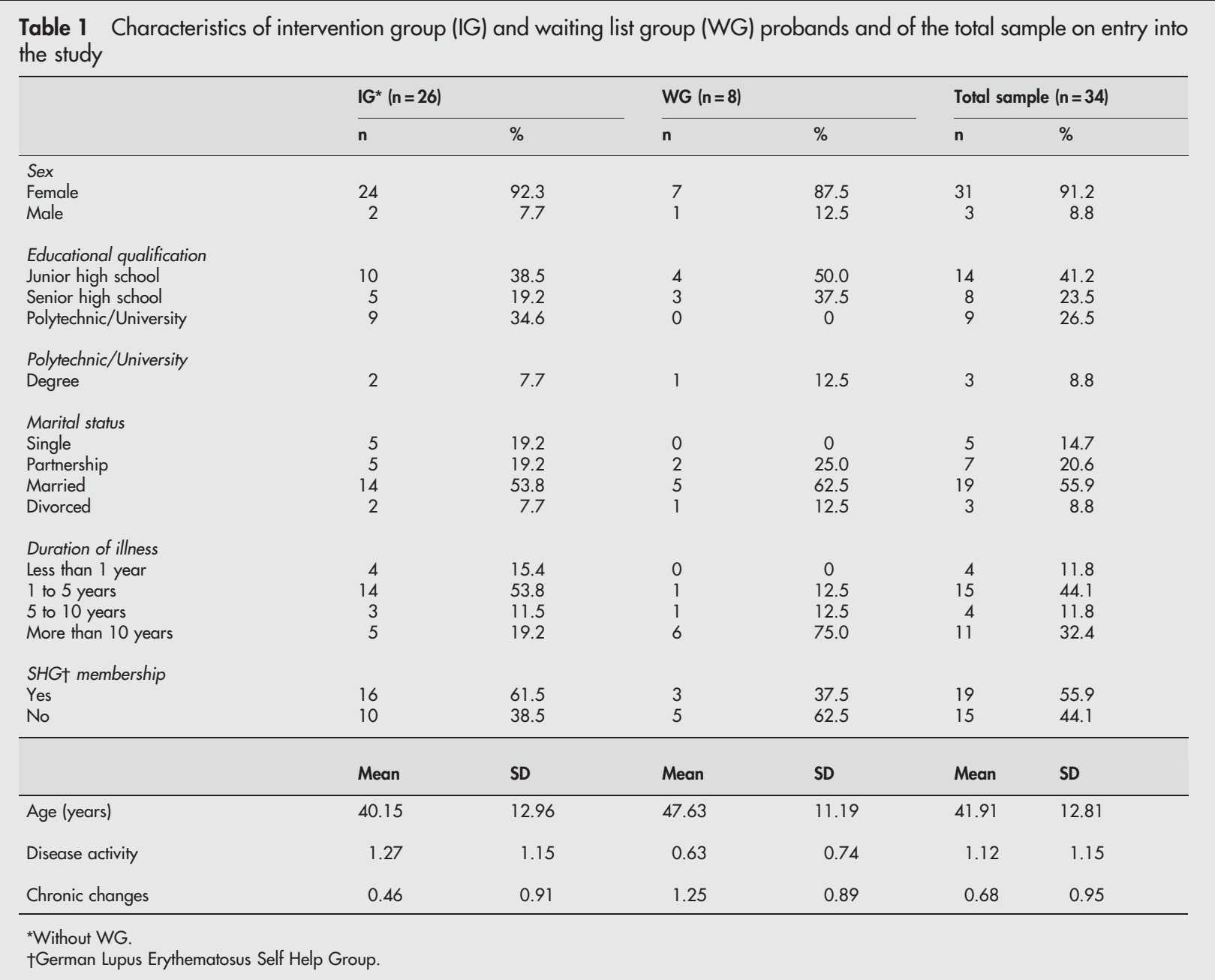

version (SCL-90-R); the short form 36 item general health questionnaire (SF-36); the hospital anxiety and depression scale-German version (HADS-D); the questionnaire for registration of control convictions relating to illness and health (KKG); the Freiburg questionnaire on coping with illness (FKV); self acceptance registration scale (SESA); and the everyday life questionnaire (FAL) with selected subscales ${ }^{49-55}$; for description see the appendix, which can be viewed as a supplemental file on the journal website (www.annrheumdis.com/supplemental). These were applied at baseline, after three months, at the end of the intervention after six months, and at a 12 month follow up. All tests used were in the form of self rating questionnaires which were filled in at home by the group participants without assistance.

The ECLAM (European consensus lupus activity measurement), a validated instrument of lupus activity, ${ }^{57}$ was used for activity (time points $0,3,6$, and 12 months), and the system lupus international collaborating clinics (SLICC)/ $\mathrm{ACR}^{58}$ for damage (time points 0 and 12 months).

At baseline, the previous history and present case records of each patient, including current treatment, were recorded. To ensure that the participants' drug treatment was kept as consistent as possible, the patients were provided with a study pass.

\section{Intervention}

The primary objective set for the psychological intervention was improvement of coping abilities of SLE patients. Concrete single targets were improved handling and control of the illness, reduced disease related and disease affecting anxieties and depression, a reduced overall mental burden, and improved interaction with relatives, partners, and other healthy persons. These dimensions were measured by FKV, SESA, HADS-D, and SCL-90-R.

Further aims were reduced disease activity and an improvement in health related quality of life, as rated by ECLAM and SF-36.

An overview of the most important psychosocial stress areas of SLE patients was gained by carrying out a comprehensive search of published reports, attending outpatient appointments, and pursuing intensive interchange with rheumatologically qualified physicians and with members of the German Lupus Erythematosus Self Help Group. This enabled some crucial problems experience by SLE patients to be formulated as a basis for the design of the following aspects.

Psychoeducational interventions: Information on symptoms, course, prognosis, and therapeutic options was given to the participants (two sessions). They collected relevant topics for further detailed information, such as efficacy and safety of pharmacological substances or correlation of psychosocial sequelae of the disease with disease outcome (one session). A greater part of this psychoeducational intervention was dedicated to the assessment and handling of the disease (three sessions). In addition, development and sustainability of social contacts and competence was target topic in further sessions (three sessions).

Psychotherapeutic interventions: These interventions consisted of sessions directed at identification and management of 
disease related/disease affecting anxieties (three sessions) and at the coping possibilities concerning fatigue and reduction of initiative and motivation in everyday living (two sessions), with structuring day activities and establishing pleasurable contacts. The participants also learned how to cope with stress and the usual everyday problems under conditions of a continuously present illness (two sessions). Coping with pain was a topic in the intervention as well (one session).

At the end of these two parts, a general discussion was conducted to enable participants to highlight problems that were still unresolved or remained unmentioned within the previous sessions (one session).

A rheumatologically qualified physician (RF-B) introduced the contents of the topic with two medical modules from the SLE patient training programme. ${ }^{38}$ All further group sessions were run by a graduate psychotherapist (SM). Topic centred discussions were held on the basis of the above mentioned units. The sessions had a semi-open structure in that orientation to the set topic was observed on the one hand while attention was paid to the individual problems confronting the participants on the other. The psychological confrontation with various aspects of coping was supplemented by an ongoing intensive interchange of information including concrete references to issues of everyday and legal relevance. This provided a down to earth, problem oriented approach to the complex topic of coping with illness.

Two intervention units with identical contents were carried out for a period of six months each: some second half probands functioned initially as a waiting list group, undergoing the intervention six months later.

Each intervention unit comprised 18 group sessions of 90 minutes' duration, the first 12 held once a week, and the other six once a fortnight. All group sessions were held in the late afternoon or early evening in small groups of not more than eight subjects. Each intervention phase was accompanied by an information evening for relatives or partners.

Because of external circumstances, the patients could not be randomised to the individual groups. Job or family situation, travel time, or regular appointments necessitated targeted distribution to appropriate weekdays. In addition, efforts were made to attain group homogeneity with respect to the age of the participants.

In view of the rare occurrence of the disease, it had to be assumed that the waiting list group could be recruited only in the course of the first intervention phase. The precondition for enrolment in the control group was a waiting time of three months or more. Patients reporting during the three months preceding the second group phase took part in the intervention but were no longer included in the waiting list group.

\section{Statistical analysis}

The characteristics of the overall sample are described using descriptive statistics. For comparison of the demographic data on the intervention and the control group, as well as on drop outs, consistent characteristics were compared using a $t$ test, and categorised data using a $\chi^{2}$ test. The $t$ test was used for the psychological course measurement, and the Wilcoxon test for the medical course measurement. Multivariate testing (general linear model for repeated measurements) was not applied as it was assumed that psychological and somatic variables were not correlated. Possible predictors of a successful treatment outcome were investigated by means of incremental regression.

Correlations were assumed to be significant at $\mathrm{p}<0.05$ error probability, very significant at $\mathrm{p}<0.01$, and highly significant at $\mathrm{p}<0.001$. Owing to the exploratory character of the present study, Bonferroni-Holm adjustments were not applied.
The software used for data analysis was the Statistical Package for the Social Sciences (SPSS, version 11.0).

\section{RESULTS}

Overall, 115 patients were asked to participate; Seventy three refused for various reasons-for example, they had no interest in participating in a scientific study. Four patients did not fulfil the psychopathological inclusion criterion (SCL$90 \mathrm{R})$. The final intervention cohort comprised 38 patients. Four patients $(10.5 \%)$ discontinued the intervention prematurely (one had a lupus flare, one found the travelling inconvenient, and two found the group setting unhelpful). There were no significant differences between the drop outs and the long term participants with respect to their demographic characteristics. Further inspection of medical and psychological data did not yield significant differences between participants and refusers.

We were able to use the datasets on 34 SLE patients for course measurements. Eight of the 34 patients who participated in the second intervention phase functioned initially as a waiting list group (WG): their psychological and medical test findings on initial contact were compared with the results at baseline. At study entry, WG did not differ substantially from the treatment group of patients (IG) (table 1$)$ despite a longer disease duration $(\mathrm{p}<0.05)$. Twenty eight of the 34 subjects were German; the other six originated from various other countries but had a good command of the German language.

\section{Measurement of the psychological course}

In view of the exploratory nature of the study, $\alpha$ adjustment according to Bonferroni-Holm was not applied.

Overall, significant effects of the intervention in terms of a reduction in mental burden, an increase in positive resources, or a decline in dysfunctional behaviour, emotions, and cognitions were recorded (table 2).

Three months after the start of the intervention, significant changes were recorded at the 5\% level on the following test scales: insecurity in social contact (SCL-90-R), social functioning (SF-36), depressive coping with the illness (FKV), and social life (FAL). Significant changes at the $1 \%$ level were detected on the following scales: somatisation, depression, anxiety, aggression, paranoid thinking, and overall mental burden (all SCL-90-R), general perception of health, emotional role function, and mental wellbeing (all SF-36) as well as depression (HADS-D). After six months, on completion of the group intervention, a marked increase in significant changes was recorded. Only the somatisation scale (SCL-90R) showed no further significant improvement over the baseline value.

Six months after completion of the intervention, most significant changes persisted or increased further, and for the first time improvement in physical role function (SF-36) and control of the disease by doctors and by self (KKG) were recorded at the $5 \%$ level.

To determine possible predictors of the degree of mental change, the following variables were investigated within the framework of a regression analysis: age, sex, education, duration of the disease, marital status, membership in the self help group, number of group sessions, participation in the information evening for relatives/partners, number of one to one discussions, and disease activity. The focus was on a correlation with the anxiety and depression scales, where, however, no significant predictors were found.

\section{Measurement of the medical course}

The measurement of the medical course of the overall sample $(\mathrm{n}=34)$ revealed no significant changes at any assessment. Changes in drug treatment and dosage were only observed in 
Table 2 Subscales/psychological course measurements $(n=34)$

\begin{tabular}{|c|c|c|c|c|}
\hline & Baseline & 3 Months & 6 Months & Follow up (12 months) \\
\hline \multicolumn{5}{|l|}{ SCL-90-R } \\
\hline Somatisation & $62.38(10.05)$ & $58.97(8.84)^{* *}$ & $60.24(10.28)$ & $58.79(10.88)^{*}$ \\
\hline Compulsion & $60.24(8.74)$ & $57.06(7.75)^{\star *}$ & $56.00(8.57)^{\star * *}$ & $56.91(9.48)^{*}$ \\
\hline Insecurity & $55.59(8.44)$ & $52.32(9.34)^{*}$ & $51.41(8.11)^{* *}$ & $52.85(9.87)$ \\
\hline Depression & $59.38(8.26)$ & $55.18(8.73)^{* *}$ & $55.47(8.37)^{\star *}$ & $55.06(10.32)^{* *}$ \\
\hline Anxiety & $58.88(9.32)$ & $54.56(8.35)^{\star *}$ & $53.56(8.34)^{\star \star *}$ & $54.59(9.33)^{* *}$ \\
\hline Aggression & $57.82(8.76)$ & $53.03(7.99)^{* *}$ & $52.85(8.35)^{\star \star}$ & $51.62(10.20)^{\star \star \star}$ \\
\hline Phobic anxiety & $54.00(9.52)$ & $52.32(7.85)$ & $50.47(8.08)^{*}$ & $50.38(8.36)^{*}$ \\
\hline Paranoid thinking & $53.65(9.32)$ & $50.62(7.38)^{\star *}$ & $49.24(7.76)^{\star \star}$ & $49.68(9.59)^{\star *}$ \\
\hline Psychoticism & $55.26(8.04)$ & $54.09(6.97)$ & $53.00(7.64)$ & $53.24(8.78)$ \\
\hline Overall mental burden (GSI) & $59.74(7.45)$ & $56.15(6.77)^{\star *}$ & $55.59(7.44)^{\star \star \star}$ & $55.41(9.54)^{\star *}$ \\
\hline \multicolumn{5}{|l|}{ SF-36 } \\
\hline Physical function & $67.79(21.57)$ & $70.00(24.83)$ & $65.74(26.26)$ & $70.88(23.40)$ \\
\hline Physical role limitation & $32.35(37.20)$ & $47.06(42.09)$ & $39.71(36.99)$ & $54.41(43.72)^{*}$ \\
\hline Pain & $45.09(24.55)$ & $48.56(26.94)$ & $49.94(26.24)$ & $54.44(29.94)$ \\
\hline General health & 39.00 (14.33) & $44.41(13.47)^{\star *}$ & $44.38(14.70)^{*}$ & $46.32(20.58)^{*}$ \\
\hline Vitality & $36.03(18.21)$ & $41.18(19.58)$ & $45.00(18.79)^{*}$ & $44.85(20.76)^{*}$ \\
\hline Social functioning & $55.12(25.40)$ & $68.01(24.07)^{*}$ & $69.12(23.68)^{*}$ & $67.65(27.20)^{*}$ \\
\hline Emotional role limitation & $50.00(42.04)$ & $75.49(37.88)^{\star \star}$ & $75.49(38.76)^{* *}$ & $75.49(37.88)^{* *}$ \\
\hline Mental health & $55.65(20.76)$ & $63.65(16.55)^{\star *}$ & $67.53(15.31)^{\star *}$ & $63.88(19.06)^{*}$ \\
\hline Change in state of health & $2.79(1.12)$ & $2.76(1.16)$ & $2.47(1.13)$ & $2.47(1.11)$ \\
\hline \multicolumn{5}{|l|}{$H A D S-D$} \\
\hline Anxiety & $7.18(3.72)$ & 6.09 (3.05) & $5.53(3.47)^{\star *}$ & $5.71(4.06)^{*}$ \\
\hline Depression & $7.26(4.60)$ & $5.97(3.95)^{\star *}$ & $5.38(3.67)^{\star \star}$ & $5.41(3.99)^{\star *}$ \\
\hline \multicolumn{5}{|l|}{$K K G$} \\
\hline Control conviction: self & $49.50(34.44)$ & $38.79(30.77)$ & $42.85(32.31)$ & $40.26(33.74)^{*}$ \\
\hline Control conviction: doctors & $81.68(22.08)$ & $77.41(26.81)$ & $74.53(29.49)$ & $74.82(26.62)^{*}$ \\
\hline Control conviction: chance/fate & $88.82(21.03)$ & $86.94(19.91)$ & $87.97(16.44)$ & $86.56(20.80)$ \\
\hline \multicolumn{5}{|l|}{ FKV } \\
\hline Depressive coping & $2.45(.77)$ & $2.24(.71)^{*}$ & $2.14(.80)^{*}$ & $2.05(.65)^{\star *}$ \\
\hline Active problem oriented coping & $3.41(.73)$ & $3.40(.83)$ & $3.45(.85)$ & $3.46(.72)$ \\
\hline Distraction/self encouragement & $3.23(.98)$ & $3.26(.72)$ & $3.35(.63)$ & $3.24(.65)$ \\
\hline Religiousness/search for meaning & $2.86(.79)$ & $2.85(.83)$ & $2.92(.87)$ & $2.88(.92)$ \\
\hline Playing down/wishful thinking & $2.61(.98)$ & $2.40(1.01)$ & $2.25(.88)^{*}$ & $2.22(.88)^{\star *}$ \\
\hline \multicolumn{5}{|l|}{ SESA } \\
\hline Self acceptance & $108.74(20.06)$ & 111.00 (19.05) & $113.06(19.26)^{*}$ & $115.91(18.03)^{* *}$ \\
\hline \multicolumn{5}{|l|}{ FAL } \\
\hline Everyday life & $32.18(7.42)$ & $34.18(7.11)$ & $33.29(7.89)$ & $34.94(7.19)^{*}$ \\
\hline Social life & $31.26(7.94)$ & $34.56(6.11)^{*}$ & $34.65(5.87)^{*}$ & $35.15(5.71)^{* *}$ \\
\hline Medical care & $10.88(3.06)$ & $11.56(2.52)$ & $11.12(2.52)$ & $11.32(2.36)$ \\
\hline
\end{tabular}

All course measurements relate to the comparison with the baseline data (comparing first/second, first/third, and first/fourth measuring time points). Significant changes: * $p<0.05{ }^{* *} p<0.01{ }^{* * *} p<0.001$.

FAL, everyday life questionnaire; FKV, Freiburg questionnaire on coping with illness; HADS-D, hospital anxiety and depression scale-German version; KKG, questionnaire for registration of control convictions relating to illness and health; SCL-90-R, symptom checklist 90 , revised version; SESA, self acceptance registration scale; SF-36, short form 36 item general health questionnaire; SLE, systemic lupus erythematosus.

three IG patients relating to their non-steroidal antiinflammatory drug (NSAID) use.

\section{Waiting list group}

The average waiting time from initial contact to baseline for the eight waiting list group members was 132 days (minimum 92, maximum 188). During this period, SF-36 revealed

\begin{tabular}{|c|c|}
\hline & Mean (SD), $n=34$ \\
\hline Information on the illness & $3.85(0.93)$ \\
\hline Help in coping with the illness & $3.91(0.75)$ \\
\hline Interchange with other patients & $4.15(0.82)$ \\
\hline Regular group sessions & $4.12(0.84)$ \\
\hline Expert group leaders & $4.68(0.64)$ \\
\hline Disease specific topics & $4.06(0.81)$ \\
\hline Feedback on test results & $3.97(0.72)$ \\
\hline Own contribution to research & $4.15(1.16)$ \\
\hline
\end{tabular}

an improvement in physical functioning and a deterioration in general perception of health (both $\mathrm{p}<0.05$ ).

\section{Course of the intervention}

The overall participation rate was $85.6 \%, 5.1 \%$ of which was disease induced. The patients attended an average of 15 group sessions (minimum 12, maximum 18). Three patients attended fewer than 14 sessions (12/12/13).

Table 3 shows the results of an anonymised concluding evaluation by those taking part in the intervention (five point Likert scale: higher rating $=$ better assessment).

\section{DISCUSSION}

The psychological group intervention presented here resulted in improvements in the mental health of SLE patients, suggesting that the intervention could be effective even over a longer period.

The primary target criterion of the study-improved coping - was achieved: coping with the disease was improved by a long term reduction in the dysfunctional strategies of "depressive coping" and "playing down/wishful thinking". In the control convictions relating to illness and health, a 
reduction in the rating of the doctor's influence was revealed at the follow up. This might be interpreted as an indication of a long term development of greater independence on the part of the patients in handling their illness. During the intervention period, a continuous reduction in anxiety and depression, and a reduction in overall mental burden, were observed. These effects were still detectable, though less pronounced, at the follow up measurement. In addition, significant improvements in social contact were also of a long term nature.

A reduction in disease activity, a secondary objective of the intervention, could not be detected by ECLAM. This may be caused by the inclusion criterion "low disease activity", aimed at ensuring continuous attendance at the group sessions, or our observation period may not have been sufficient to register effects of improved coping on the course of the disease. However, our data are in accordance with studies by Dobkin et $a l^{47}$ and Sohng. ${ }^{42}$ Six month follow up assessments within the framework of other studies ${ }^{44} 45$ revealed significant improvements in various medical aspects, but without the disease activity of the probands being investigated.

Another secondary objective, improvement in the health related quality of life, was achieved in essential selective aspects. For instance, general perception of health, vitality, social functioning, emotional role function, and mental wellbeing were improved throughout the intervention and in part at the follow up measurement.

In comparison with existing offers of support for SLE patients, ${ }^{38-47}$ the present intervention is closest in its structure and objectives to the study design of Dobkin et al..$^{47}$ Despite a concept successfully used with cancer patients and uniformly trained group leaders, Dobkin and colleagues achieved no significant improvements in the 58 members of the intervention group in comparison with their control group, either from the mental or from the physical aspect. This may have reflected the fact that the Canadian trial ${ }^{47}$ had specified no psychopathological findings as an inclusion criterion. However, each proband of our intervention had to record a clinically atypical value on at least one SCL-90-R scale to enable a potential therapeutic benefit of the group sessions to be detected. It is also conceivable that the contents of the intervention by Dobkin et $a l_{,}{ }^{47}$ which had originally been developed for cancer patients, failed fully to meet the specific problems of SLE patients.

However, with respect to a secondary objective of the same study-reduced illness intrusiveness-Edworthy et $a t^{48}$ achieved statistically significant effects. For example, the areas (1) relationships and personal development (family relationships, other social relationships, self expression) and (2) intimacy (relationship with spouse, sex life) underwent a marked improvement. These effects were not significant until the six or 12 month follow up.

The development of the present intervention was based on the following considerations: in view of the complexity and diversity of potential psychosocial problems in SLE patients, an integrative psychosocial approach seemed inadequate, even though a recent study reported significant effects on couple communication and self efficacy ${ }^{59}$; with a telephone based intervention, the advantages of a group setting are lost; and the brief supportive expressive group psychotherapy approach was not originally developed for SLE patients and failed, despite the relevant adaptation, to produce the desired success. ${ }^{47}$ In view of the important role of social support, ${ }^{27-29}$ it was considered essential to integrate key attachment figures. Factors supporting the concept selected for the present study are the low drop out rate, the high level of participation in the accompanying information session for relatives, and the very positive evaluation of its adequacy by the patients (table 3 ).
In comparison with the baseline psychological findings, several significant changes were recorded after only half of the intervention period, whereas maximum effects were not achieved until the end of the six month intervention (table 2). The time frame of the study thus appears to do greater justice to the complex problems of SLE patients than shorter interventions, and this is also supported by the predominant stability of the attained effects at the six month follow up.

Weaknesses of the present study are primarily in its small sample size and small waiting list group which has not been rigorously followed up and which does not fulfil standard criteria for a control group. However, the sample size is relatively large for a single centre study, considering the rare nature of the disease and the amount of time that had to be invested by the probands. The fact that a correction of the $\alpha$ level was not applied in the data analysis seems justified in view of the exploratory nature of the study.

In summary, the results of this newly developed intervention aimed at improving the coping abilities of SLE patients are promising. In comparison with reported psychological intervention, the current study is based on a longer psychoeducational approach with a focus not just limited to information and practical aspects of coping with the illness, addressing patients who have documented serious psychological problems. What is now needed is replication within the framework of a confirmatory study with a larger sample and a randomised control group approach, possibly with a longer term follow up of the achieved effects.

\section{ACKNOWLEDGEMENTS}

We are indebted to Ms Borgi Winkler-Rohlfing, Chairwoman of the German Lupus Erythematosus Self Help Group, for several intensive discussions which had a crucial impact on the design of the group intervention. Sincere thanks are also due to Prof Dr Volker Tschuschke, Chair of Medical Psychology, University of Cologne, Germany, who provided valuable incentives for the evaluation of the study. We also thank Susan Griesbach for help in the copy editing of the manuscript.

This study was funded by the Alfried Krupp Foundation.

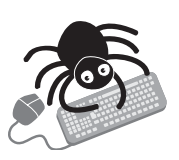

The appendix can be viewed on the journal website: www.annrheumdis.com/supplemental

\section{Authors' affiliations}

S Millen*, D Falagan, R Fischer-Betz, M Schneider, Department of Rheumatology, Heinrich-Heine-University, Düsseldorf, Germany M Haupt*, M Jänner, Outpatient Department of Psychiatry and Psychotherapy, Heinrich-Heine-University

*The first two authors contributed equally to this paper

\section{REFERENCES}

1 Wysenbeek AJ, Leibovici L, Weinberger A, Guedj D. Fatigue in systemic lupus erythematosus. Prevalence and relation to disease expression. BrJ Rheumatol 1993;32:633-5.

2 McKinley PS, Ouellette SC, Winkel GH. The contributions of disease activity, sleep patterns, and depression to fatigue in systemic lupus erythematosus. A proposed model. Arthritis Rheum 1995;38:826-34.

3 Wang B, Gladman DD, Urowitz MB. Fatigue in lupus is not correlated with disease activity. J Rheumatol 1998;25:892-5.

4 Bruce IN, Mak VC, Hallett DC, Gladman DD, Urowitz MB. Factors associated with fatigue in patients with systemic lupus erythematosus. Ann Rheum Dis 1999;58:379-81.

5 Zonana-Nacach A, Roseman JM, McGwin G, Friedman AW, Baethge BA, Reveille JD, et al. Systemic lupus erythematosus in three ethnic groups. VI. Factors associated with fatigue within 5 years of criteria diagnosis. LUMINA Study Group. Lupus in minority populations: nature vs nurture, Lupus 2000;9:101-9.

6 Tayer WG, Nicassio PM, Weisman MH, Schuman C, Daly J. Disease status predicts fatigue in systemic lupus erythematosus. J Rheumatol 2001;28:1999-2007. 
7 Omdal R, Waterloo K, Koldingsnes W, Husby G, Mellgren SI. Fatigue in patients with systemic lupus erythematosus: the psychosocial aspects. $J$ Rheumatol 2003;30:283-7.

8 Valencia-Flores M, Resendiz M, Castano VA, Santiago V, Campos RM, Sandino $S$, et al. Objective and subjective sleep disturbances in patients with systemic lupus erythematosus. Arthritis Rheum 1999;42:2189-93.

9 Tench CM, McCurdie I, White PD, D'Cruz DP. The prevalence and associations of fatigue in systemic lupus erythematosus. Rheumatology (Oxford) 2000;39:1249-54.

10 Tench C, Bentley D, Vleck V, McCurdie I, White P, D'Cruz D. Aerobic fitness, fatigue, and physical disability in systemic lupus erythematosus. J Rheumato 2002;29:474-81.

11 Denburg SD, Carbotte RM, Denburg JA. Psychological aspects of systemic lupus erythematosus: cognitive function, mood, and self-report. J Rheumatol 1997;24:998-1003.

12 Brey RL, Holliday SL, Saklad AR, Navarrete MG, Hermosillo-Romo D, Stallworth CL, et al. Neuropsychiatric syndromes in lupus: prevalence using standardized definitions. Neurology 2002;58:1214-20.

13 Karlson EW, Daltroy LH, Lew RA, Wright EA, Partridge AJ, Fossel AH, et al. The relationship of socioeconomic status, race, and modifiable risk factors to outcomes in patients with systemic lupus erythematosus. Arthritis Rheum 1997;40:47-56.

14 Burckhardt CS, Archenholtz B, Bjelle A. Quality of life of women with systemic lupus erythematosus: comparison with women with rheumatoid arthritis. $J$ Rheumatol 1993;20:977-81.

15 Wekking EM, Vingerhoets AJ, van Dam AP, Nossent JC, Swaak AJ. Daily stressors and systemic lupus erythematosus: a longitudinal analysis - first findings. Psychother Psychosom 1991;55:108-13.

16 Omdal R, Husby G, Mellgren SI. Mental health status in systemic lupus erythematosus. Scand J Rheumatol 1995;24:142-5.

17 Tayer WG, Nicassio PM, Radojevic V, Krall T. Pain and helplessness as correlates of depression in systemic lupus erythematosus. Br J Health Psychol 1996;1:253-62.

18 Waterloo K, Omdal R, Husby G, Mellgren SI. Emotional status in systemic lupus erythematosus. Scand J Rheumatol 1998;27:410-14.

19 Dobkin PL, Fortin PR, Joseph L, Esdaile JM, Danoff DS, Clarke AE. Psychosocial contributors to mental and physical health in patients with systemic lupus erythematosus. Arthritis Care Res 1998;11:23-31.

20 Shortall E, Isenberg D, Newman SP. Factors associated with mood and mood disorders in SLE. Lupus 1995;4:272-9.

21 Adams SG, Dammers PM, Saia TL, Brantley PJ, Gaydos GR. Stress, depression, and anxiety predict average symptom severity and daily symptom fluctuation in systemic lupus erythematosus. J Behav Med 1994;17:459-77.

22 Abu-Shakra M, Mader R, Langevitz P, Friger M, Codish S, Neumann L, et al. Quality of life in systemic lupus erythematosus: a controlled study. J Rheumatol 1999;26:306-9.

23 Karassa FB, Magliano M, Isenberg DA. Suicide attempts in patients with systemic lupus erythematosus. Ann Rheum Dis 2003;62:58-60.

24 McCracken LM, Semenchuk EM, Goetsch VL. Cross-sectional and longitudinal analyses of coping responses and health status in persons with systemic lupus erythematosus. Behav Med 1995;20:179-87.

25 Dobkin PL, Da Costa D, Dritsa M, Fortin PR, Senecal JL, Goulet JR, et al. Quality of life in systemic lupus erythematosus patients during more and less active disease states: differential contributors to mental and physical health. Arthritis Care Res 1999;12:401-10

26 Da Costa D, Dobkin PL, Fitzcharles MA, Fortin PR, Beaulieu A, Zummer M, et al. Determinants of health status in fibromyalgia: a comparative study with systemic lupus erythematosus. J Rheumatol 2000;27:365-72.

27 Sutcliffe N, Clarke AE, Levinton C, Frost C, Gordon C, Isenberg DA. Associates of health status in patients with systemic lupus erythematosus. J Rheumatol 1999:26:2352-6.

28 Bae SC, Hashimoto H, Karlson EW, Liang MH, Daltroy LH. Variable effects of social support by race, economic status, and disease activity in systemic lupus erythematosus. J Rheumatol 2001;28:1245-51.

29 Thumboo J, Fong KY, Chan SP, Leong KH, Feng PH, Thio ST, et al. A prospective study of factors affecting quality of life in systemic lupus erythematosus. J Rheumatol 2000;27:1414-20.

30 Dobkin PL, Da Costa D, Fortin PR, Edworthy S, Barr S, Esdaile JM, et al. Living with lupus: a prospective pan-Canadian study. J Rheumatol 2001;28:2442-8.

31 Ward MM, Marx AS, Barry NN. Psychological distress and changes in the activity of systemic lupus erythematosus. Rheumatology (Oxford) 2002;41:184-8

32 Herrmann M, Scholmerich J, Straub RH. Stress an rheumatic diseases. Rheum Dis Clin North Am. 2000;26: 737-63, viii.

33 Pawlak CR, Witte T, Heiken H, Hundt M, Schubert J, Wiese B, et al. Flares in patients with systemic lupus erythematosus are associated with daily psychological stress. Psychother Psychosom 2003;72:159-65.
34 Meusling U. Psychosoziale Belastungen und psychologische Interventionsmöglichkeiten beim systemischen Lupus erythematodes, 1st ed. Berlin: Koester, 1995.

35 Da Costa D, Dobkin PL, Pinard L, Fortin PR, Danoff DS, Esdaile JM, et al. The role of stress in functional disability among women with systemic lupus erythematosus: a prospective study. Arthritis Care Res 1999;12:112-19.

36 Ishikura R, Morimoto N, Tanaka K, Kinukawa N, Yoshizawa S, Horiuchi T, ef al. Factors associated with anxiety, depression and suicide ideation in female outpatients with SLE in Japan. Clin Rheumatol 2001;20:394-400.

37 Langer HE. Patientenschulung - Ein Beitrag zur Verbesserung der Langzeitbetreuung von Rheumapatienten. Z Rheumatol 1995;54:207-12.

38 Thieme K und Arbeitsgruppe SLE-Patientenschulung. Das SLEPatientenschulungsprogramm - Programminhalt und erste Evaluationsergebnisse. Akt Rheumatol 1997;22:98-104.

39 Crofts P, D'Cruz D. Systemic lupus erythematosus. Part 2. The role of the nurse. Nurs Stand 1997;11:40-4.

40 Matussek S, Sattel B, Schuster P. Alltagsbewaeltigung und Lebensperspektiven. Seminar fuer Betroffene mit einer chronischen rheumatischen Erkrankung. Bonn: Deutsche Rheuma-Liga Bundesverband e.V., 1992.

41 Braden CJ, McGlone K, Pennington F. Specific psychosocial and behavioral outcomes from the systemic lupus erythematosus self-help-course. Health Educ Q 1993;20:29-41.

42 Sohng KY. Effects of a self-management course for patients with systemic lupus erythematosus. J Adv Nurs 2003;42:479-86.

43 Maisiak R, Austin JS, West SG, Heck L. The effect of person-centered counseling on the psychological status of persons with systemic lupus erythematosus or rheumatoid arthritis. Arthritis Care Res 1996:9:60-6.

44 Austin JS, Maisiak R, Macrina DM, Heck L. Health outcome improvements in patients with systemic lupus erythematosus using two telephone counseling interventions. Arthritis Care Res 1996;9:391-9.

45 Maisiak RS, Overman LB. Reduced risk of hospitalization for lupus patients during a patient counseling intervention. Arthritis Rheum 2000;43:S178.

46 Overman LB, Maisiak RS. The effects of patient counseling on coping behavior and health status in lupus patients. Arthritis Rheum 2000;43:S179.

47 Dobkin PL, Da Costa D, Joseph L, Fortin PR, Edworthy S, Barr S, et al. Counterbalancing patient demands with evidence: results from a panCanadian randomized clinical trial of brief supportive-expressive group psychotherapy for women with systemic lupus erythematosus. Ann Behav Med 2002;24:88-99.

48 Edworthy SM, Dobkin PL, Clarke AE, Costa DD, Dritsa M, Fortin PR, et al. Group psychotherapy reduces illness intrusiveness in systemic lupus erythematosus. J Rheumatol 2003;30:1011-16.

49 Franke G. Die Symptom-Checkliste von Derogatis - deutsche Version, 2nd ed. Goettingen: Beltz Test, 2002.

50 Bullinger M, Kirchberger I. SF-36 - Fragebogen zum Gesundheitszustand. Handanweisung, 1st ed. Goettingen: Hogrefe, 1998.

51 Herrmann C, Buss U, Snaith RP. HADS-D: hospital anxiety and depression scale - Deutsche version. Ein Fragebogen zur Erfassung von Angst und Depressivität in der somatischen Medizin. Testdokumentation und Handanweisung, 1st ed. Bern: Huber, 1995.

52 Lohaus A, Schmitt GM. Fragebogen zur Erhebung von Kontrollueberzeugungen zu Krankheit und Gesundheit (KKG) Handanweisung, 1st ed. Goettingen: Hogrefe, 1989.

53 Muthny FA. Freiburger Fragebogen zur Krankheitsverarbeitung, FKV Manual, 1st ed. Weinheim: Beltz, 1989.

54 Sorembe V, Westhoff K. Skala zur Erfassung der Selbstakzeptierung (SESA), 1 st ed. Goettingen: Hogrefe, 1985.

55 Bullinger M, Kirchberger I, v Steinbuechel N. The everyday-life questionnaire (EDLQ) - an instrument for the assessment of health related quality of life. Z Med Psychol 1993;3:121-31.

56 Vitali C, Bencivelli W, Isenberg DA, Smolen JS, Snaith ML, Sciuto M, et al. Disease activity in systemic lupus erythematosus: report of the Consensus Study Group of the European Workshop for Rheumatology Research. II. Identification of the variables indicative of disease activity and their use in the development of an activity score. The European Consensus Study Group for Disease Activity in SLE. Clin Exp Rheumatol 1992;10:541-7.

57 Gladman D, Ginzler E, Goldsmith C, Fortin P, Liang M, Urowitz M, et al. The development and initial validation of the Systemic Lupus International Collaborating Clinics/American College of Rheumatology damage index for systemic lupus erythematosus. Arthritis Rheum 1996;39:363-9.

58 Karlson EW, Liang MH, Eaton H, Huang J, Fitzgerald L, Rogers MP, et al. A randomized clinical trial of a psychoeducational intervention to improve outcomes in systemic lupus erythematosus. Arthritis Rheum 2004;50: 1832-41. 